\section{Endo-biliary stents for benign disease: not always benign after all!}

\author{
Jo-Etienne Abela, John E. Anderson, \\ Henry R. Whalen, Kenneth G. Mitchell \\ Department of Surgery, Royal Alexandra \\ Hospital, Paisley, UK
}

\section{Abstract}

This case report describes the presentation, management and treatment of a patient who suffered small bowel perforation due to the migration of his biliary stent which had been inserted for benign disease.

\section{Introduction}

Choledocholithiasis is a common complication of gall stone disease. In most cases stones are removed from the common bile duct by endoscopic retrograde cholangiopancreatography (ERCP) and sphincterotomy prior to cholecystectomy. However, in around 5\% of cases this is not possible or the patient is too unfit to undergo surgery. In these cases a stent can be used to provide biliary decompression. This case report illustrates one of the rare dangers of biliary stent migration and highlights the importance of careful follow-up of patients treated with long-term plastic endo-biliary stents.

\section{Case Report}

A 75-year-old male presented with acute pain in the right lower abdominal quadrant associated with pyrexia, vomiting and constipation. The patient was known to our unit with a history of post-cholecystectomy pain but this acute presentation was not in keeping with his previous hospital admissions. His past medical history was positive for morbid obesity, chronic obstructive airway disease, Class III congestive heart failure and a trauma laparotomy and partial splenectomy many years previously. His biliary disease was complex. Five years previous to this current admission he was diagnosed with gall-stones which required an emergency open sub-total cholecystectomy and a series of ERCP's for lithotripsy and bile duct stenting. At his last ERCP, six months prior to this acute admission, it was noted that his latest stent was not in position and that his biliary tree was clear.
On examination, the patient had a core temperature of $39^{\circ} \mathrm{C}$ and appeared dehydrated. He was not jaundiced. His chest examination was unremarkable apart from scattered wheezes. His abdomen was distended and exquisite tenderness with muscle guarding was elicited in the right lower quadrant. His blood tests confirmed normal liver function tests and amylase. His white cell count and C-reactive protein were elevated. Plain radiography of the chest excluded a significant pneumoperitoneum. On his plain abdominal radiograph there was evidence of non-specific bowel dilatation and a straight plastic stent was seen in the right lower quadrant (Figure 1). An urgent computed tomography (CT) scan confirmed migration of the biliary stent into the distal ileum and was suggestive of visceral perforation with localised free fluid and pneumoperitoneum (Figure 2).

At laparotomy the affected distal ileum was found in an adhesive cocoon secondary to previous surgery. The straight plastic stent had eroded through into the general peritoneal cavity (Figure 3). It was removed and the enterotomy repaired with a simple sutured closure. Careful adhesiolysis and peritoneal lavage were performed. The patient's postoperative recovery was otherwise uneventful.

\section{Discussion}

Foreign bodies tend to pass through the intestine rapidly and without complication. Blocked biliary stents become stiff and lose their original malleability and as a result may exert pressure on the intestinal wall and ultimately erode through it by pressure necrosis. In our patient small bowel peristalsis was unable to negotiate this rigid stent through the distal ileum. As Figure 3 illustrates, the ileum was rendered particularly tortuous and angulated secondary to adhesions formed after the two previous laparotomies.

Endo-biliary stent migration is a recognised sequel following endotherapy of bile duct calculi and strictures. Fortunately, visceral perforation appears to be uncommon if not rare. Duodenal perforation may occur intra-peritoneally or retroperitoneally. ${ }^{1-3}$ Perforation through the small bowel is also well documented and may present inside hernial defects. ${ }^{4-8}$ Colonic perforation appears to be reported less frequently. ${ }^{9,10}$ Endoscopic retrieval of stents from the duodenum and colon may be feasible. However, endoscopic retrieval from the small bowel to our knowledge this has not been reported yet and would presumably require balloon enteroscopy.

This case highlights the importance of stent retrieval after successful bile duct clearance and the importance of careful follow-up in
Correspondence: John E. Anderson, Department of Surgery, Monklands District General Hospital, Monkscourt Avenue, Airdrie, ML6 0JS, UK.

Tel. + 44.123.674.8748

E-mail: jandersuk@yahoo.co.uk

Key words: slipped endo-biliary stent.

Received for publication: 26 September 2011 Accepted for publication: 18 October 2011.

This work is licensed under a Creative Commons Attribution NonCommercial 3.0 License (CC BYNC 3.0).

(C)Copyright J.E. Abela et al., 2011

Licensee PAGEPress, Italy

Clinics and Practice 2011; 1:e102

doi:10.4081/cp.2011.e102

patients treated with long-term plastic endobiliary stents especially in those patients who develop abdominal pain which is not classically biliary in character. This is even more important in those patients with previous abdominal surgery. In this group of patients we advocate thorough investigation with plain and axial imaging to exclude stent migration. In patients with retained migrated stents we recommend retrieval by endoscopic or operative means in order to avert life-threatening complications.

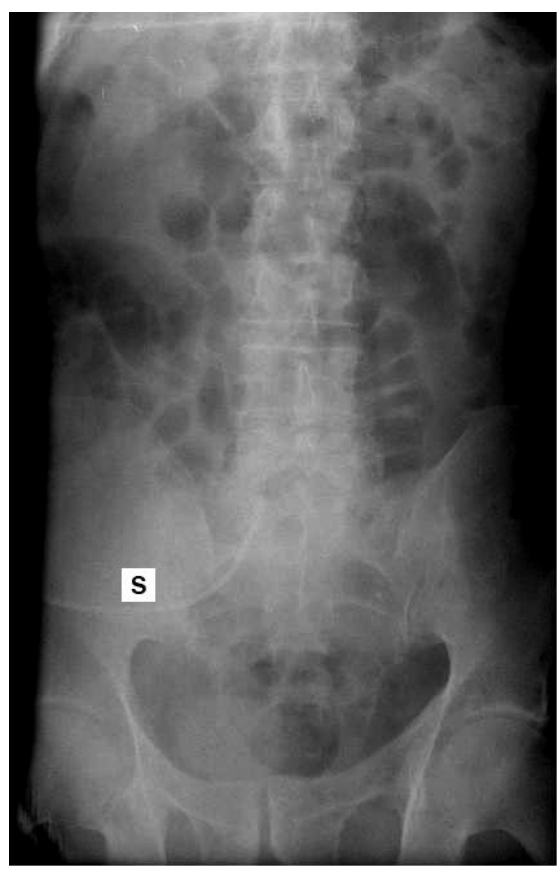

Figure 1. Plain abdominal radiograph showing stent $(S)$ migration to the right lower abdominal quadrant. 


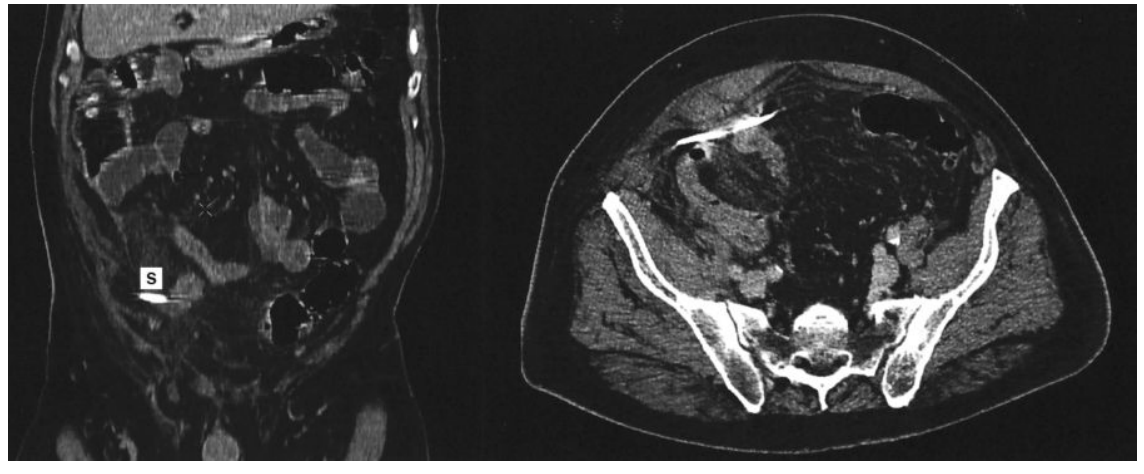

Figure 2. Computed tomography scans showing stent $(S)$ perforating through the distal ileum with localised fluid collection and pneumoperitoneum.

\section{References}

1. Lo CH, Chung S, Bohmer RD. A devastating complication: duodenal perforation due to biliary stent migration. Surg Laparosc Endosc Percutan Tech 2008;18: 608-10.

2. Bharathi RS, Rao PP, Ghosh K. Intra-peritoneal duodenal perforation caused by delayed migration of endobiliary stent: a case report. Int J Surg 2008;6:478-80.

3. Basile A, Macri A, Lamberto S, et al. Duodenoscrotal fistula secondary to retroperitoneal migration of an endoscopi- cally placed plastic biliary stent. Gastrointest Endosc 2003;57:136-8.

4. Levey JM. Intestinal perforation in a parastomal hernia by a migrated plastic biliary stent. Surg Endosc 2002;16:1636-7.

5. Storkson RH, Edwin B, Reiertsen 0, et al. Gut perforation caused by biliary endoprosthesis. Endoscopy 2000;32:87-9.

6. Lanteri R, Naso P, Rapisarda C, et al. Jejunal perforation for biliary stent dislocation. Am J Gastroenterol 2006;101:908-9.

7. Akimboye F, Lloyd T, Hobson S, Garcea G. Migration of endoscopic biliary stent and small bowel perforation within an incision-

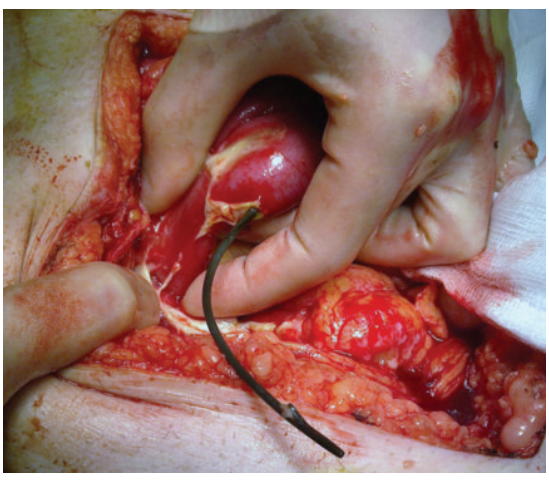

Figure 3. Laparotomy - distal ileum involved in post-operative adhesions with stent eroding into general peritoneal cavity.

al hernia. Surg Laparosc Endosc Percutan Tech 2006;16:39-40.

8. Akbulut S, Cakabay B, Ozmen CA, et al. An unusual cause of ileal perforation: report of a case and literature review. World $\mathrm{J}$ Gastroenterol 2009;15:2672-4.

9. Anderson EM, Phillips-Hughes J, Chapman R. Sigmoid colonic perforation and pelvic abscess complicating biliary stent migration. Abdom Imaging 2007;32: 317-9.

10. Aryal KR, Sherlock DJ. A case of colonic perforation from biliary stent. Endoscopy 2008;40 Suppl 2:E54. 